\title{
Mercury contamination imposes structural shift on the microbial community of an agricultural soil
}

\author{
Lateef Babatunde Salam ${ }^{1 *}$, Halima Shomope ${ }^{2 \dagger}$, Zainab Ummi ${ }^{2 \dagger}$ and Fatima Bukar ${ }^{2 \dagger}$
}

\begin{abstract}
Background: The purpose of this study is to use shotgun next-generation sequencing to unravel the microbial community structure of an agricultural soil, decipher the effects of mercury contamination on the structure of the microbial community and the soil physicochemistry and heavy metals content.

Results: The soil physicochemistry after mercury contamination revealed a shift in soil pH from neutral $(6.99 \pm 0.001)$ to acidic (5.96 \pm 0.25), a decline in moisture content to $<4 \%$, and a significant decrease in the concentrations of all the macronutrients and the total organic matter. Significant decrease in all the heavy metals detected in the agricultural soil was also observed in mercury inundated SL3 microcosm. Structural analysis of the metagenomes of SL1 (agricultural soil) and SL3 (mercury-contaminated agricultural soil) using Illumina shotgun next-generation sequencing revealed the loss due to mercury contamination of $54.75 \%$ of the microbial community consisting of an archaeal domain, 11 phyla, 12 classes, 24 orders, 36 families, 59 genera, and 86 species. The dominant phylum, class, genus, and species in SL1 metagenome are Proteobacteria, Bacilli, Staphylococcus, and Sphingobacterium sp. 21; while in SL3 metagenome, Proteobacteria, Alphaproteobacteria, Singulisphaera, and Singulisphaera acidiphila were preponderant. Mercury contamination resulted in a massive upscale in the population of members of the phylum Planctomycetes and the genera Singulisphaera, Brevundimonas, Sanguibacter, Exiguobacterium, Desulfobacca, and Proteus in SL3 metagenome while it causes massive decline in the population of genera Staphylococcus and Brachybacterium.
\end{abstract}

Conclusions: This study revealed that mercury contamination of the agricultural soil imposed selective pressure on the members of the microbial community, which negatively impact on their population, alter soil physicochemistry, and enriched sizable numbers of members of the community that are well adapted to mercury stress. It also reveals members of microbial community hitherto not reported to be important in mercury detoxification process.

Keywords: Agricultural soil, Soil microcosm, Illumina shotgun sequencing, Mercury contamination

\section{Introduction}

The release of heavy metals into the environment through agricultural and industrial operations and the consequences of these pollution on ecosystems and human health are sources of serious concern (Robinson and Tuovinen 1984; Lapanje et al. 2010). In agriculture, mercurial compounds have been used as insecticides,

\footnotetext{
* Correspondence: babssalaam@yahoo.com

† Halima Shomope, Zainab Ummi and Fatima Bukar contributed equally to this work.

'Department of Biological Sciences, Microbiology unit, Summit University, Offa, Nigeria

Full list of author information is available at the end of the article
}

fungicides, herbicides, and bactericides, resulting in severe localized mercury pollution in soils (Bryan and Langston 1992). Other agricultural practices such as application of fertilizers, lime, sludges, and manures are also sources of mercury in soil (Azevedo and Rodriguez 2012). Soil plays an important role in the biogeochemical cycle of mercury acting as both a sink and a source of mercury to biota, atmosphere, and hydrological compartments. However, mercury speciation, accumulation, and transformation and the interaction of the various species with the soil matrix cause changes in solubility, toxicity, and bioavailability of the metal and make it difficult to decipher the effects of mercury contamination 
on the soil microbial community (Nies 1999; Biester et al. 2002; Barkay et al. 2003; Lapanje et al. 2010).

Essential heavy metals such as zinc, copper, iron, and chromium are important to life. They play an integral role in metabolic processes and are essential micronutrients and cofactors of several enzymes, required in redox processes and stabilization of molecules through electrostatic interactions and regulation of osmotic pressure (Bruins et al. 2000; Romaniuk et al. 2018). However, heavy metals with no known biological function such as mercury are very toxic to the cell. In humans, mercury toxicity results in gene expression alteration, kidney damage, tremor, restlessness, anxiety, numbness in hand and feet, total brain damage in early exposure, localized brain damage in late exposure, and death upon exposure to high doses (Weiss et al. 2002; Curtis and Klaassen 2010). In microorganisms, mercury toxicity results in protein denaturation, cell envelope disruption, inhibition of cell division and enzyme activities, destruction of nucleic acids, and transcription inhibition (Khan et al. 2009; Gundacker et al. 2010; Bánfalvi 2011; Wyszkowska et al. 2013; Yuan et al. 2015). In plants, exposure to mercury reduces photosynthesis, transpiration rate, water uptake, and chlorophyll synthesis. It also causes loss of potassium, magnesium and manganese and accumulation of iron (Boening 2000). High affinity of mercury with sulfydryl $(\mathrm{SH})$ groups form the $\mathrm{S}-\mathrm{Hg}-\mathrm{S}$ bridge, which disrupts the stability of the group and affects seed germination and embryo's growth. Furthermore, in plants, mercury is known to affect the antioxidant defense system interfering with the modulation of the non-enzymatic antioxidants glutathione, non-protein thiols, and the enzymatic antioxidants superoxide dismutase, ascorbate peroxidase, and glutathione reductase (Ortega-Villasante et al. 2005; Sparks 2005; Israr et al. 2006).

It is widely believed that mercury contamination in soils impacts negatively on the richness and diversity of the microbial community (Rasmussen and Sorensen 2001; Rasmussen et al. 2008). To validate this claim, we set up an investigation using next-generation shotgun metagenomic approach to decipher the microbial community structure of an agricultural soil (SL1), and to monitor the effects of mercury contamination $(250 \mathrm{mg}$ ) on the microbial community structure of the agricultural soil (SL3).

\section{Materials and methods}

\section{Sampling site description}

Soil samples were collected from an agricultural farm at Mandate estate, Ilorin, Nigeria. The coordinates of the sampling site were latitude $8^{\circ} 28^{\prime} 24.81^{\prime \prime} \mathrm{N}$ and longitude $4^{\circ} 29^{\prime} 58.87^{\prime \prime}$ E. Farming history at the sampling site dated back to 20-25 years and crops such as maize, cassava, yam, and vegetables were grown.

\section{Source of heavy metal}

Mercury (II) chloride $\left(\mathrm{HgCl}_{2}\right)$, the source of mercury used in this study was purchased from Sigma Aldrich Corp (St Louis, MO, USA).

\section{Sampling and Microcosm Set up}

Soil samples were collected from upper 10-12 cm using a sterile hand trowel after removing the debris from the soil surface. Soil sample was passed through a $2 \mathrm{~mm}$ mesh sieve. The sieved soil was thoroughly mixed in a large plastic bag to avoid variability among the results of replicate soil samples and was used without air drying. Sieved soil $(1 \mathrm{~kg})$ weighed and placed in an open aluminum pan was designated SL1. The second soil microcosm designated SL3 contain $1 \mathrm{~kg}$ of sieved soil amended with $250 \mathrm{mg} \mathrm{HgCl}_{2}$. The two setups (in triplicates) were incubated at room temperature for 4 weeks and flooded weekly with $50 \mathrm{ml}$ distilled water to maintain a moisture content of $25 \%$. Physicochemistry and heavy metal content of the agricultural soil was determined as described previously (Salam et al. 2014).

\section{DNA extraction and Shotgun metagenomics}

Total DNA used for metagenomic analysis was extracted directly from the two soil microcosms, SL1 and SL3. Total DNA was extracted from the agricultural soil (SL1) immediately after sampling to determine the microbial community structure of the agricultural soil prior to amendment with mercury. For soil microcosm SL3 containing agricultural soil amended with $250 \mathrm{mg}$ mercury, total DNA was extracted 4 weeks post contamination to determine the effects of the mercury amendment on the microbial community structure. Total DNA was extracted from the sieved soil samples $(0.25 \mathrm{~g})$ using ZYMO soil DNA extraction Ki (Model D 6001, Zymo Research, USA) following manufacturer's instructions. Extracted total DNA concentration and quality was ascertained using NanoDrop spectrophotometer and electrophoresed on a $0.9 \%(w / v)$ agarose gel consecutively. Shotgun metagenomics of SL1 and SL3 microcosms were prepared using the Illumina Nextera XT sample processing kit and sequenced on a MiSeq. The protocols for total DNA preparation for Illumina shotgun sequencing were as described previously (Salam 2018; Salam and Ishaq 2019).

Processing of raw reads, quality control, assembly, and taxonomic classification

Processing and quality control of raw reads, assembly, and taxonomic classification were carried out using the analysis tools in EDGE Bioinformatics web server (Li et al. 2017). The pre-processing of the raw Illumina fastq file of the two metagenomes (SL1 and SL3) for quality control check, de novo assembly of the trimmed reads, and assembly validation were carried out using FastQ 
Quality Control Software (FaQCs) (Lo and Chain 2014), IDBA-UD (Peng et al. 2012), and Bowtie2 (Langmead and Salzberg 2012), respectively.

Read-based and contig-based classifications in the EDGE Bioinformatics web server were deployed for taxonomic classification of the SL1 and SL3 metagenomes. All the classification tools GOTTCHA (Freitas et al. 2015), Kraken (Wood and Salzberg 2014), MetaPhIAN (Segata et al. 2012), and BWA (Li and Durbin 2009) indicated for read-based classification were deployed (using their default parameters) to decipher the taxonomic affiliation of the metagenomes. Contig-based classification is based on the alignment of the SL1 and SL3 contigs to NCBI's RefSeq database using the BWA-mem aligner. Metagenomic data of SL1 and SL3 have been deposited and made public in EDGE Bioinformatics web server.

\section{Results}

\section{Physicochemistry and heavy metals content}

The physicochemistry and heavy metal content of the agricultural soil (SL1) and mercury-contaminated agricultural soil (SL3) are shown in Table 1. The $\mathrm{pH}$ of the soil, which is very close to neutral $(6.99 \pm 0.001)$ in SL1 became slightly acidic in SL3 $(5.96 \pm 0.25)$. The moisture content, which is less than $7 \%(6.83 \pm 0.01)$ in SL1 dropped further to $<4 \%$ in SL3 $(3.14 \pm 0.01)$. All the other physicochemical parameters also a showed decreasing trend in SL3 (Table 1). In addition, there are

Table 1 Dynamics of physicochemical properties and heavy metal content of agricultural soil (SL1) and mercury-inundated agricultural soil (SL3)

\begin{tabular}{lll}
\hline & $\mathrm{SL} 1$ & $\mathrm{SL3}$ \\
\hline Physicochemical parameters & & \\
$\mathrm{pH}$ & $6.99 \pm 0.31$ & $5.96 \pm 0.25$ \\
Moisture (\%) & $6.83 \pm 0.01$ & $3.14 \pm 0.01$ \\
Total organic matter (\%) & $75.62 \pm 0.63$ & $43.38 \pm 0.58$ \\
Total nitrogen (\%) & $58.49 \pm 1.43$ & $17.63 \pm 0.80$ \\
Phosphorus (mg/kg) & $30.49 \pm 1.54$ & $9.53 \pm 1.35$ \\
Potassium (mg/kg) & $19.75 \pm 0.004$ & $4.03 \pm 0.001$ \\
Heavy metal content & & \\
Mercury (mg/kg) & $\mathrm{ND}$ & $52.5 \pm 0.003$ \\
Lead $(\mathrm{mg} / \mathrm{kg})$ & $0.05 \pm 0.001$ & $\mathrm{ND}$ \\
Chromium (mg/kg) & $5.50 \pm 0.003$ & $1.6 \pm 0.004$ \\
Cadmium (mg/kg) & $0.21 \pm 0.002$ & $0.035 \pm 0.002$ \\
Zinc (mg/kg) & $16.49 \pm 0.003$ & $3.28 \pm 0.004$ \\
Iron (mg/kg) & $13.45 \pm 0.003$ & $2.52 \pm 0.004$ \\
Copper (mg/kg) & $13.04 \pm 0.004$ & $2.74 \pm 0.005$ \\
Selenium (mg/kg) & $0.008 \pm 0.001$ & $\mathrm{ND}$ \\
\hline
\end{tabular}

significant traces of heavy metals in the soil. While the concentrations of lead $(0.05 \pm 0.001 \mathrm{mg} / \mathrm{kg})$ and selenium $(0.008 \pm 0.001 \mathrm{mg} / \mathrm{kg})$ detected in the agricultural soil are significantly low, high concentrations of zinc, iron, copper, and chromium were observed in the agricultural soil. However, the concentrations of the heavy metals substantially decrease in SL3 (Table 1).

\section{General features of the metagenomes}

Illumina shotgun next-generation sequencing of the total DNA from the two soil microcosms revealed 46,292 and 27,220 sequence reads for SL1 and SL3, respectively. The SL1 and SL3 metagenomes consisted of 13,787,457 and 7, $604,708 \mathrm{bp}$, mean sequence length of $297.84 \pm 27.40$ and $279.38 \pm 72.10 \mathrm{bp}$, and mean GC contents of $54.77 \% \pm$ 7.14 and $52.82 \% \pm 16.09$, respectively. After trimming, dereplication, and quality control, sequence reads in SL1 and SL3 reduced to 45,795 (98.93\%) and 25,075 (92.12\%) with 13,769,735 (99.87\%) and 7,529,285 (99.01\%) bp, mean sequence lengths of $300.68 \pm 1.78$ and $300.27 \pm 10.25 \mathrm{bp}$, and mean GC contents of $55.33 \% \pm 4.48$ and $57.23 \% \pm$ 5.34 , respectively. Other general features of the metagenomes are indicated in Table 2.

\section{Taxonomic classification of the metagenomes}

Inundation of the agricultural soil with mercury significantly alters the structure of the soil microbiome. Taxonomic characterization of the agricultural soil (SL1) revealed 28 phyla with the predominance of the phyla Proteobacteria (41.55\%), Firmicutes (31.46\%), Actinobacteria (15.00\%), Bacteroidetes (7.64\%), and Candidatus Saccharibacteria (1.84\%). In mercury-contaminated SL3 microcosm, 17 phyla were recovered with Proteobacteria (56.55\%), Planctomycetes (14.67\%), Actinobacteria (11.79\%), Bacteroidetes (11.46\%), and Firmicutes (5.36\%) preponderant. While the population of the phyla Candidatus Saccharibacteria, Acidobacteria, Chloroflexi, and Firmicutes decrease by $\geq 90 \%$ in SL3 microcosm, there is an exponential increase in the population of the phylum Planctomycetes in the mercury-amended soil (Figure 1).

In class delineation, 40 classes were retrieved from SL1 microcosm with the dominance of Bacilli (26.55\%), Gammaproteobacteria (24.12\%), Actinobacteria (16.23\%), Alphaproteobacteria (9.72\%), and Betaproteobacteria (7.80\%). In mercury-contaminated SL3 microcosm where 28 classes were recovered, Alphaproteobacteria (24.14\%), Gammaproteobacteria (21.69\%), Planctomycetia (15.23\%), Actinobacteria (12.24\%), and Sphingobacteriia (10.04\%) were preponderant (Figure 2). There is a massive decline in the population of members of the class Bacilli as it dipped by $>90 \%$ in SL3 microcosm, while the population of members of the classes Gemmatimonadetes and Methanomicrobia (belonging to Archaea domain) completely disappeared. However, there is an exponential and 
Table 2 General features of SL1 and SL3 metagenomes

\begin{tabular}{|c|c|c|}
\hline & SL1 & SL3 \\
\hline \multicolumn{3}{|l|}{ 1.Pre-processing } \\
\hline \multicolumn{3}{|l|}{ a. Raw reads } \\
\hline Reads & 46,292 & 27,220 \\
\hline Total bases (bp) & $13,787,457$ & $7,604,708$ \\
\hline Mean read length (bp) & $297.84 \pm 27.40$ & $279.38 \pm 72.10$ \\
\hline Mean GC content (\%) & $54.77 \pm 7.14$ & $52.82 \pm 16.09$ \\
\hline \multicolumn{3}{|l|}{ b. Quality trimming } \\
\hline \multicolumn{3}{|l|}{ Trimmed reads } \\
\hline Reads & $45,795(98.93 \%)$ & $25,075(92.12 \%)$ \\
\hline Total bases (bp) & $13,769,735$ (99.87\%) & $7,529,285(99.01 \%)$ \\
\hline Mean read length (bp) & $300.68 \pm 1.78$ & $300.27 \pm 10.25$ \\
\hline Mean GC content (\%) & $55.33 \pm 4.48$ & $57.23 \pm 5.34$ \\
\hline Paired reads & 45,784 (99.98\%) & 24,976 (99.61 \%) \\
\hline Paired total bases & $\begin{array}{l}13,766,902(99.98 \\
\%)\end{array}$ & $\begin{array}{l}7,510,110(99.75 \\
\%)\end{array}$ \\
\hline Unpaired reads & $11(0.02 \%)$ & $99(0.39 \%)$ \\
\hline Unpaired total bases & $2,833(0.02 \%)$ & $19,175(0.25 \%)$ \\
\hline \multicolumn{3}{|l|}{2 Assembly and annotation } \\
\hline \multicolumn{3}{|c|}{ a. De novo assembly by idba_ud } \\
\hline Number of contigs & 68 & 38 \\
\hline N50 (bp) & 423 & 424 \\
\hline Max contig size (bp) & 465 & 458 \\
\hline Min contig size (bp) & 326 & 262 \\
\hline Total assembly size (bp) & 27,929 & 15,691 \\
\hline \multicolumn{3}{|c|}{ b. Assembly validation by read mapping } \\
\hline $\begin{array}{l}\text { Number of mapped } \\
\text { reads }\end{array}$ & 31,315 & 15,774 \\
\hline$\%$ of Total reads & $68.38 \%$ & $62.91 \%$ \\
\hline $\begin{array}{l}\text { Number of unmapped } \\
\text { reads }\end{array}$ & 14,480 & 9,301 \\
\hline$\%$ of Total reads & $31.62 \%$ & $37.09 \%$ \\
\hline Average fold coverage & $276.60 x$ & $275.14 \times$ \\
\hline
\end{tabular}

significant increase in the population of members of the classes Planctomycetia and Alphaproteobacteria in the mercury-contaminated SL3 microcosm.

In order classification, 83 orders were recovered in SL1 microcosm. The dominant orders are Bacillales (26.37\%), Actinomycetales (15.02\%), Enterobacteriales (9.78\%), Micrococcineae (6.09\%), and Sphingobacteriales (6.08\%). In mercury-contaminated SL3 microcosm where 59 orders were retrieved, Planctomycetales (16.17\%), Actinomycetales (12.44\%), Caulobacterales (11.45\%), Sphingobacteriales (10.66\%), and Enterobacteriales (8.35\%), were dominant. In SL3 microcosm, there is a massive decrease by $91 \%$ and
$98 \%$ in the population of members of Bacillales and Xanthomonadales, respectively, as well as extinction of several other orders. However, massive upscale in sequence reads of Planctomycetales and significant increase in the population of members of Syntrophobacterales and Caulobacterales were observed in SL3 metagenome (Figure 3).

In family delineation, 137 families were recovered from SL1 microcosm. The predominant families are Staphylococcaceae (23.11\%), Enterobacteriaceae (12.54\%), Sphingobacteriaceae (6.11\%), Bacillaceae (5.38\%), and Alcaligenaceae (4.93\%). In mercury-contaminated SL3 microcosm where 102 families were retrieved, Planctomycetaceae (19.81\%), Caulobacteraceae (14.03\%), Sphingobacteriaceae (11.71\%), and Enterobacteriaceae (10.22\%) were dominant. Massive decline in the population of members of Staphylococcaceae (99.69\%), Microbacteriaceae (86.7\%), and Dermabacteraceae $(99.75 \%)$ families were observed in SL3. Contrastively, there is a massive upscale in the sequence reads of Planctomycetaceae and a significant increase in the population of members of the families Sanguibacteraceae, Caulobacteraceae, Phyllobacteriaceae, Syntrophaceae, and few others (Figure 4).

Mercury contamination of the agricultural soil resulted in a significant shift in its microbial community structure. In agricultural soil (SL1) microcosm where 213 genera were recovered, the genera Staphylococcus (29.65\%), Sphingobacterium (4.59\%), Pseudomonas (4.28\%), Pedobacter (3.30\%), and Caulobacter (2.70\%) were dominant. However, in mercury-contaminated (SL3) microcosm where 154 genera were retrieved, the genera Singulisphaera (16.61\%), Brevundimonas (10.04\%), Sphingobacterium (9.48\%), Pedobacter (7.71\%), and Caulobacter $(7.18 \%)$ were preponderant. There is massive reduction in the population of Staphylococcus (99.71\%) and Brachybacterium (99.75\%) and several others in SL3. In contrast, mercury contamination massively enriched the population of Singulisphaera, Proteus, Desulfobacca, Brevundimonas, Sanguibacter, Caulobacter, and few others in SL3 metagenome (Figure 5).

In species delineation of the metagenomic reads, 242 and 156 species were recovered from SL1 and SL3 metagenomes, respectively. The dominant species in SL1 are Sphingobacterium sp. 21 (9.16\%), Pedobacter saltans (6.57\%), Brevundimonas subvibrioides (5.04\%), and Brachybacterium faecium (4.33\%). In mercury-amended SL3, the predominant species are Singulisphaera acidiphila (22.85\%), Brevundimonas subvibrioides (13.80\%), Sphingobacterium sp. 21 (13.04\%), and Pedobacter saltans (10.34\%) (Figure 6).

Contig-based taxonomic classification of the metagenomes (SL1 and SL3) conducted by aligning the SL1 and SL3 contig to NCBI's RefSeq database using the BWA-mem aligner is indicated in Additional file 1: Figs. S1-S6. 


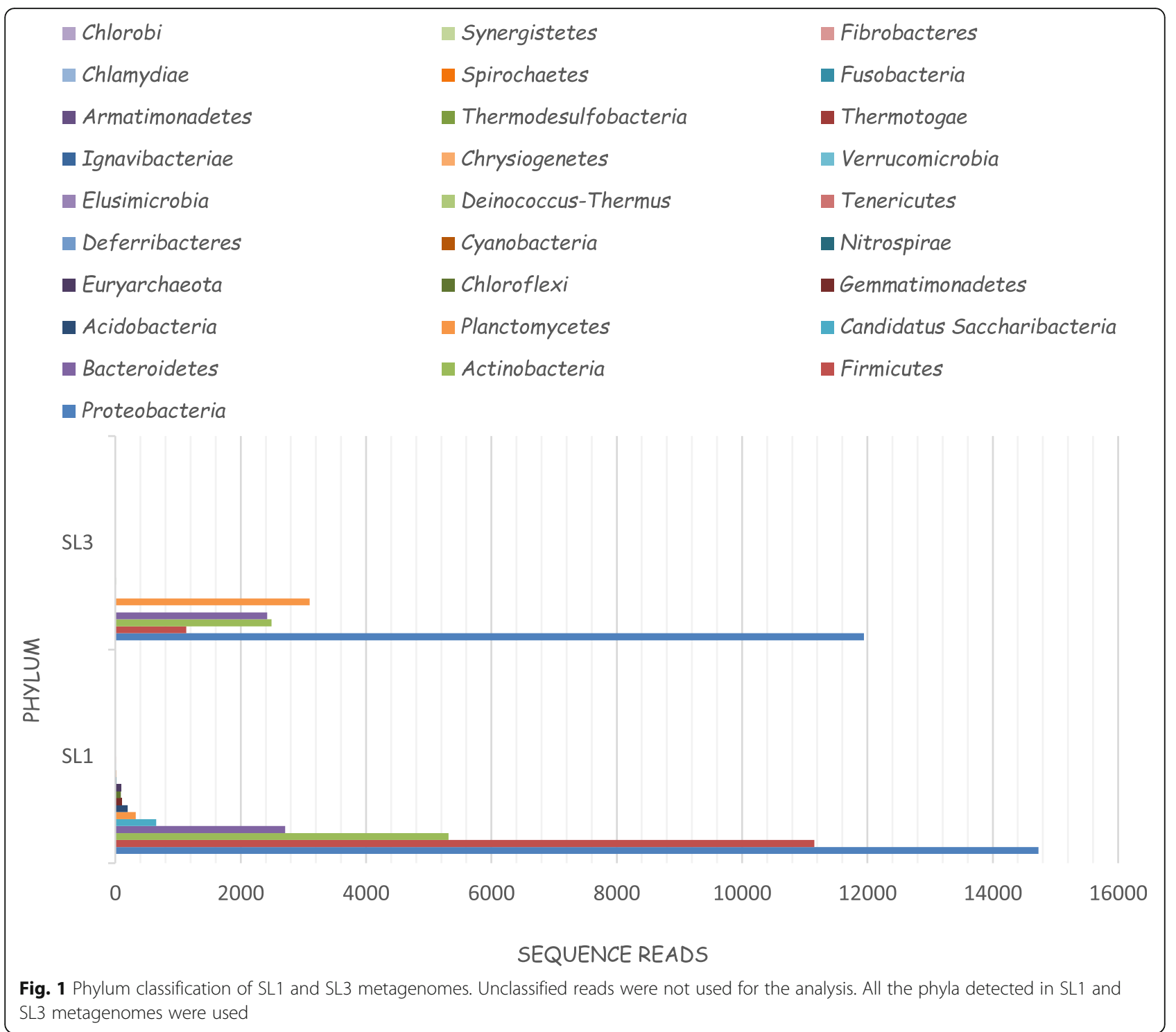

\section{Discussion}

Inundation of agricultural soils with various concentrations of heavy metal ions via waste disposal, bush burning, manure and fertilizer application, as well as pesticide and herbicide application affects soil ecosystem processes, alters soil physicochemistry, reduces microbial richness and diversity, with consequences on biogeochemical cycling and ecosystem balance (Babich and Stozzky 1985; Giller et al. 1998; Lapanje et al. 2010). In this study, all the physicochemical parameters significantly reduce in mercury-amended SL3 microcosm. This may be attributed to mercury contamination. For instance, several authors have averred that organic matter plays a dominant role in the binding of mercury in soils at it often forms stable complexes with organic ligands (Wang et al. 1997; Boszke et al. 2003; Dreher and Follmer 2004) especially where the $\mathrm{pH}$ of the soil is $<7$
(Gabriel and Williamson 2004). More so, dissolution of metal ions in soil and complexation of the mercury salt with essential soil nutrients such as nitrates and phosphates will lower the $\mathrm{pH}$ of the soil and render the nutrients inaccessible to microorganisms (Andrew and Jackson 1996; Salam and Ishaq 2019).

Heavy metal content analysis of the agricultural soil reveals the presence of various heavy metals such as lead, chromium, cadmium, copper, zinc, and selenium though at concentrations not above the permissible threshold for soils (WHO/FAO 2001; UNEP 2013; Toth et al. 2016). This may be attributed to various agricultural practices such as fertilizer application, manure application, bush burning, and pesticide and herbicide application, among others that introduce the heavy metals to the agricultural soil. The concentrations of these metals drastically reduced in SL3 mercury- 


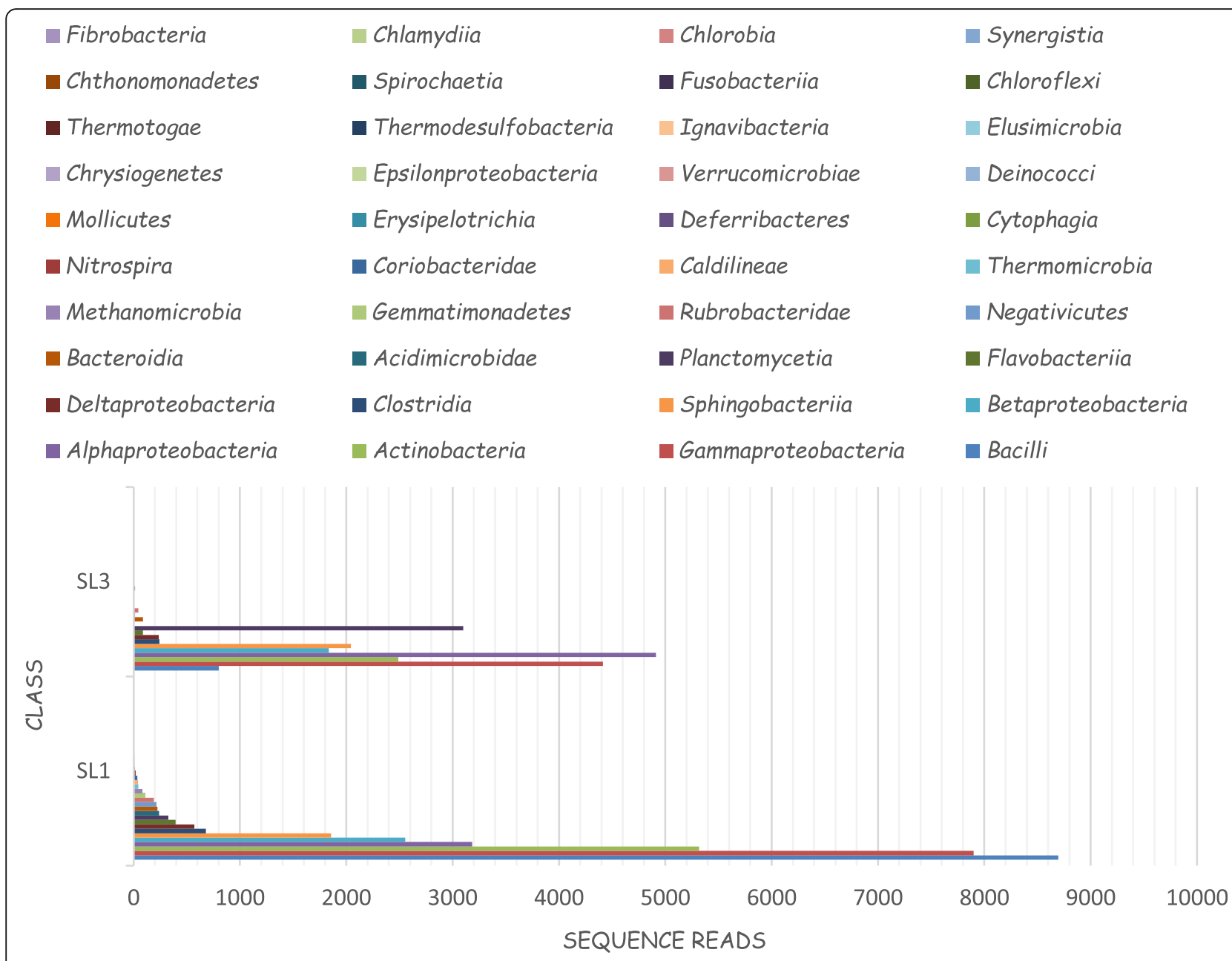

Fig. 2 Class classification of SL1 and SL3 metagenomes. Unclassified reads were not used for the analysis. All the classes detected in SL1 and SL3 metagenomes were used

amended soil. This may be due to heavy metal tolerance/resistance of some members of the microbial community. Heavy metals such as zinc, copper, iron, and chromium are essential micronutrients and cofactors of several enzymes and are important in redox processes, stabilization of molecules through electrostatic interactions, and regulation of osmotic pressure (Bruins et al. 2000). However, non-essential heavy metals with no known biological functions such as lead, cadmium, and mercury are very toxic with deleterious effects on microorganisms such as protein denaturation, cell envelope disruption, inhibition of cell division and enzyme activities, destruction of nucleic acids, and transcription inhibition (Khan et al. 2009; Gundacker et al. 2010; Banfalvi 2011; Wyszkowska et al. 2013; Yuan et al. 2015). The ability of the microbial community in SL3 to maintain intracellular homeostasis of the essential heavy metals and normalize resistance against toxic heavy metals is predicated on diverse resistance mechanisms such as chromosomal/plasmid mediated efflux systems that pump the toxic metal ions from microbial cells, enzymatic biotransformation of metals to less toxic species, and incorporation of heavy metals into complexes by metal-binding proteins, which makes them less toxic to the cell (Nies and Silver 1995; Silver and le Phung 2005; Dziewit and Drewniak 2016).

Mercury contamination of SL1 agricultural soil resulted in the loss of $54.75 \%$ of the microbial community consisting of an archaeal domain, 11 phyla, 12 classes, 24 orders, 36 families, 59 genera, and 86 species. Previous reports have indicated that exposure of microbial communities to mercury contamination results in an initial decline in microbial numbers followed by enrichment and rapid growth of mercury-resistant subpopulations with relatively low genetic diversity of mercury-adapted communities as consequence (Rasmussen and Sorensen 2001; Rasmussen et al. 2008). Mercury compounds $\left(\mathrm{Hg}^{2+}\right)$, on gaining access to the cell, form covalent bond with cysteine residues of proteins and deplete cellular antioxidants (Valko et al. 2006). This results in oxidative stress to microbial cells 


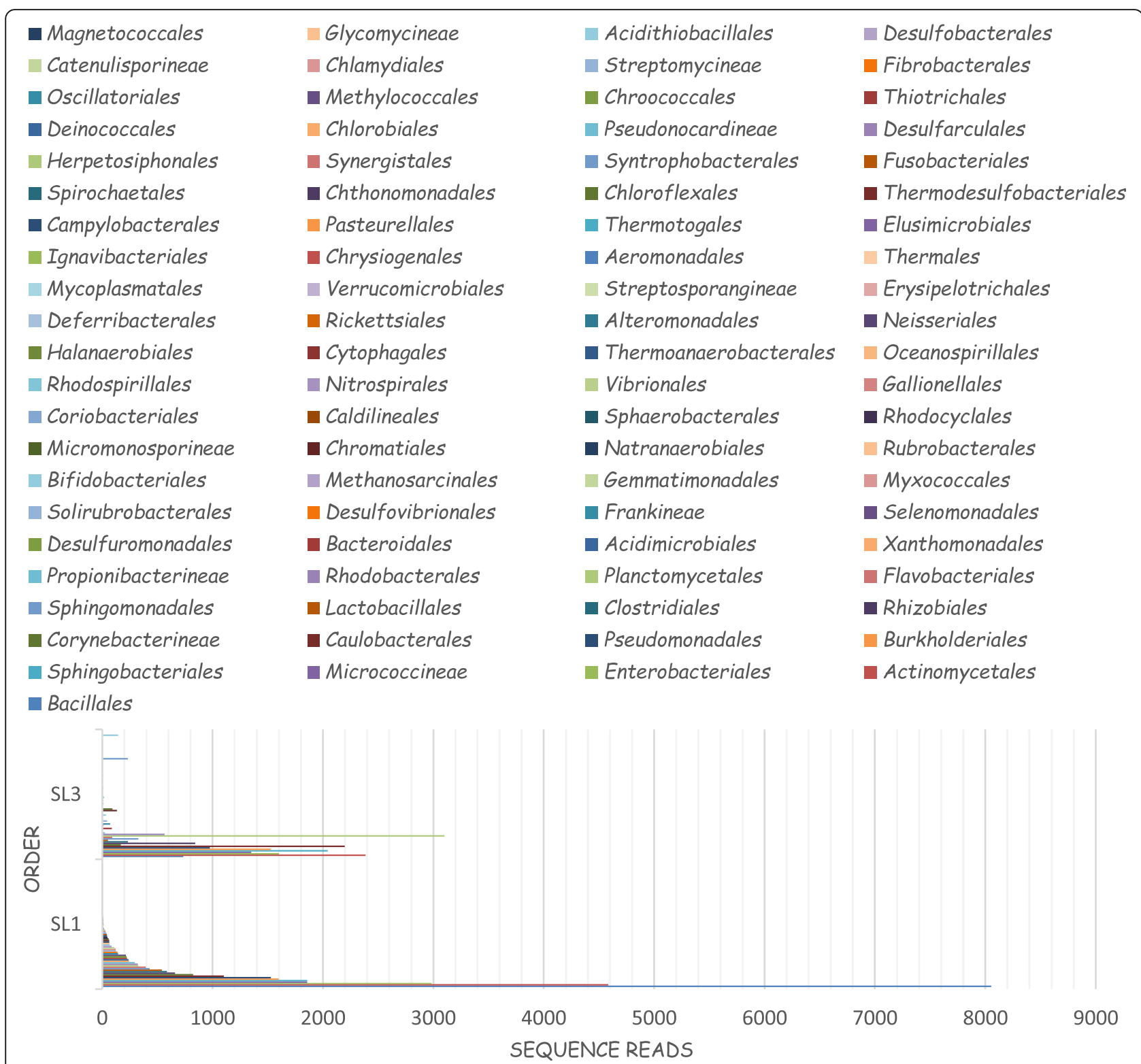

Fig. 3 Order classification of SL1 and SL3 metagenomes. Unclassified reads were not used for the analysis. All the orders detected in SL1 and SL3 metagenomes were used

due to imbalance between pro- and anti-oxidant homeostasis (Fashola et al. 2016). This perhaps explains the massive reduction in the population of dominant genera in agricultural soil SL1 such as Staphylococcus, Geobacillus, Streptococcus, Brachybacterium, Flavobacterium, and many others in mercury-contaminated SL3.

The predominance of the phyla Proteobacteria and Firmicutes in the agricultural soil is expected as these phyla are replete with members that are well adapted to agricultural soils (Cheema et al. 2015; Trivedi et al. 2016; Salam et al. 2017; Yin et al. 2017). This is due to their huge physiological, morphological, and metabolic diversity; ability to survive in oligotrophic environments; ability to utilize diverse low molecular weight and high molecular weight recalcitrant carbon compounds prevalent in soils; and ability to survive adverse environmental conditions and resist desiccation caused by sharp variation in soil surface temperature (Fierer et al. 2007; Spain et al. 2009; Eilers et al. 2010; Goldfarb et al. 2011; Aislabie and Deslippe 2013; Montecchia et al. 2015). While the phylum Proteobacteria loses $19 \%$ of its members due to mercury contamination in SL3, it still constitutes the highest population (57\%) in SL3 metagenome. Interestingly, 90\% of the members of the phylum Firmicutes in SL3 were lost, while surprisingly, those of the phylum Planctomycetes were massively enriched in SL3 metagenome. The massive increase 


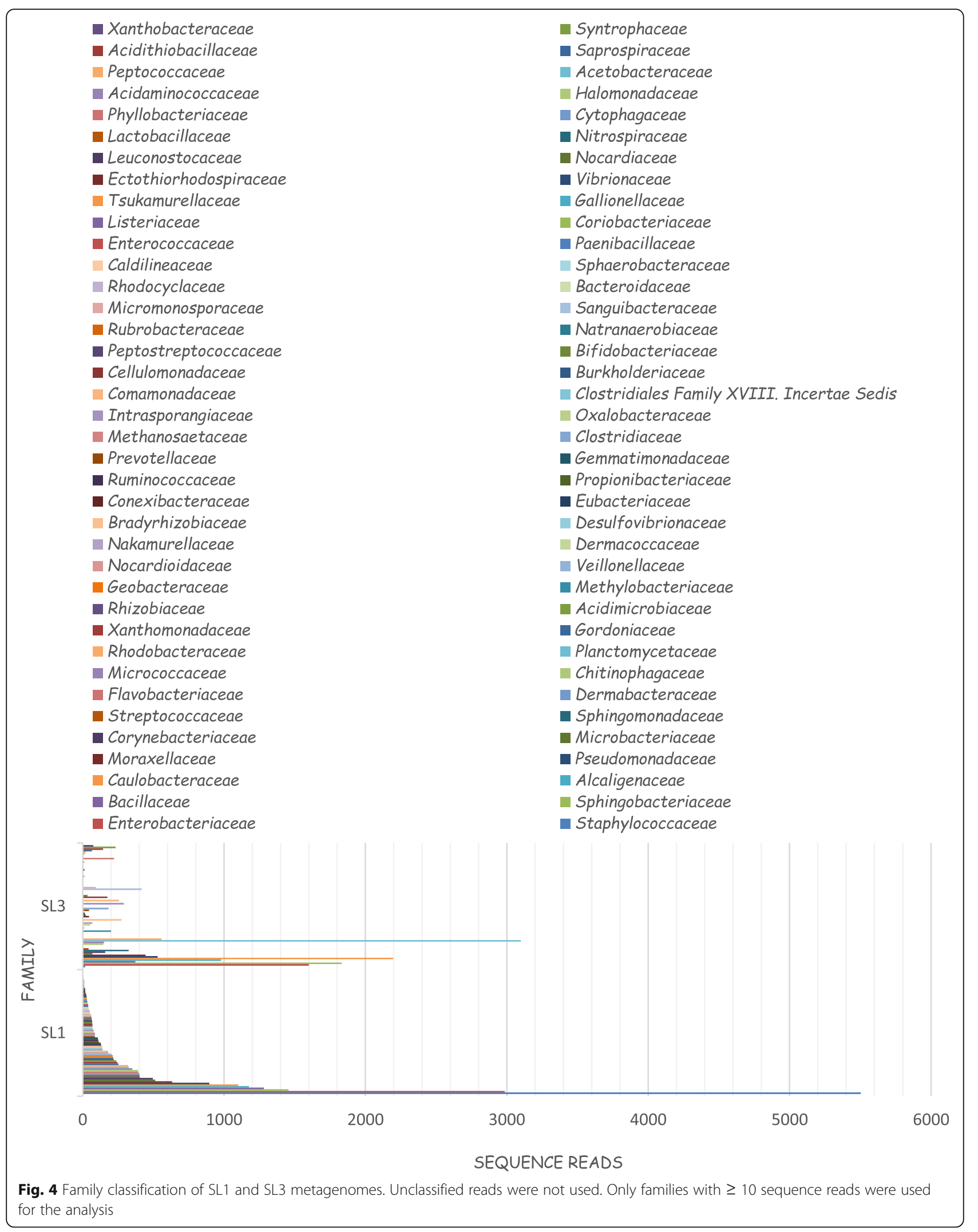




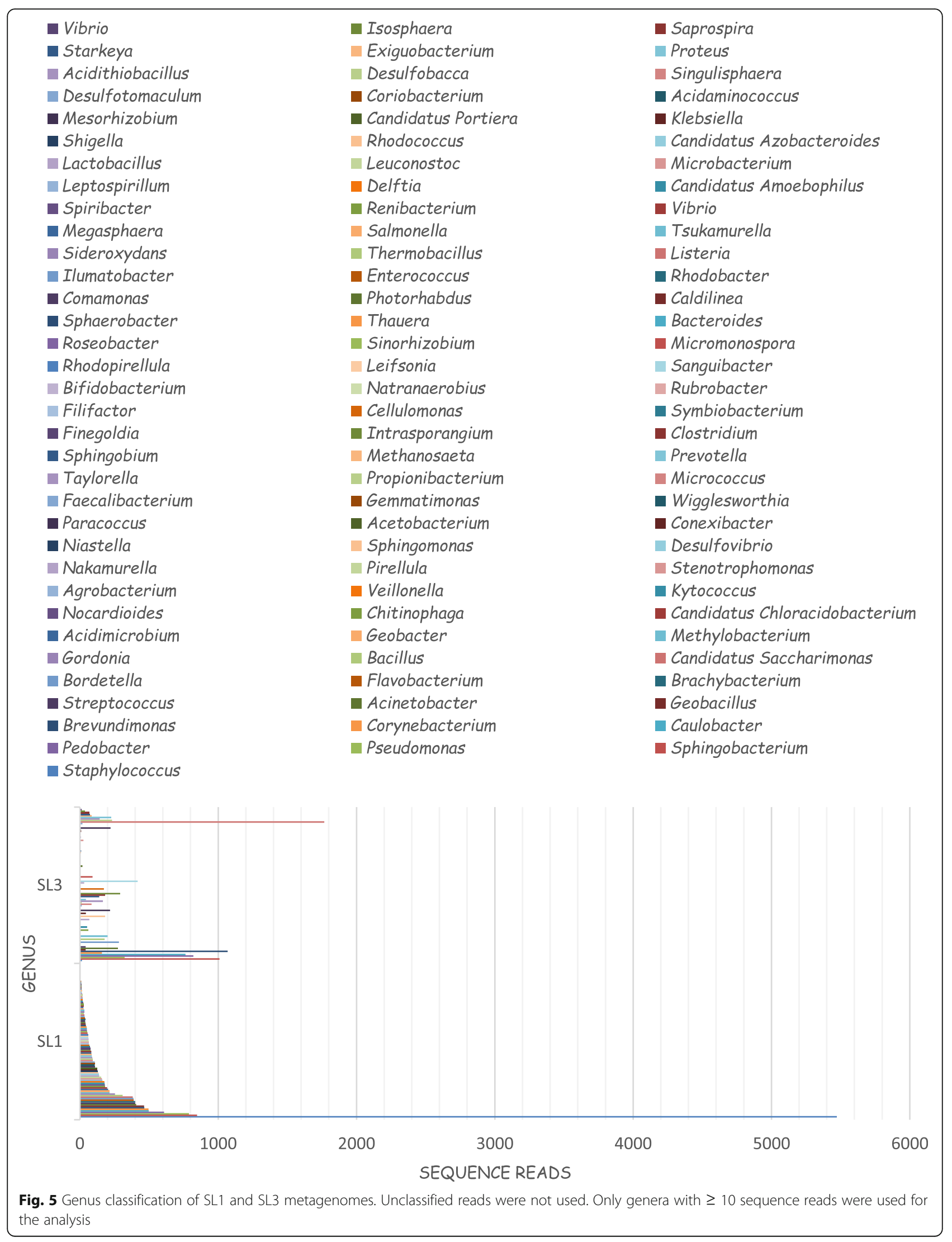




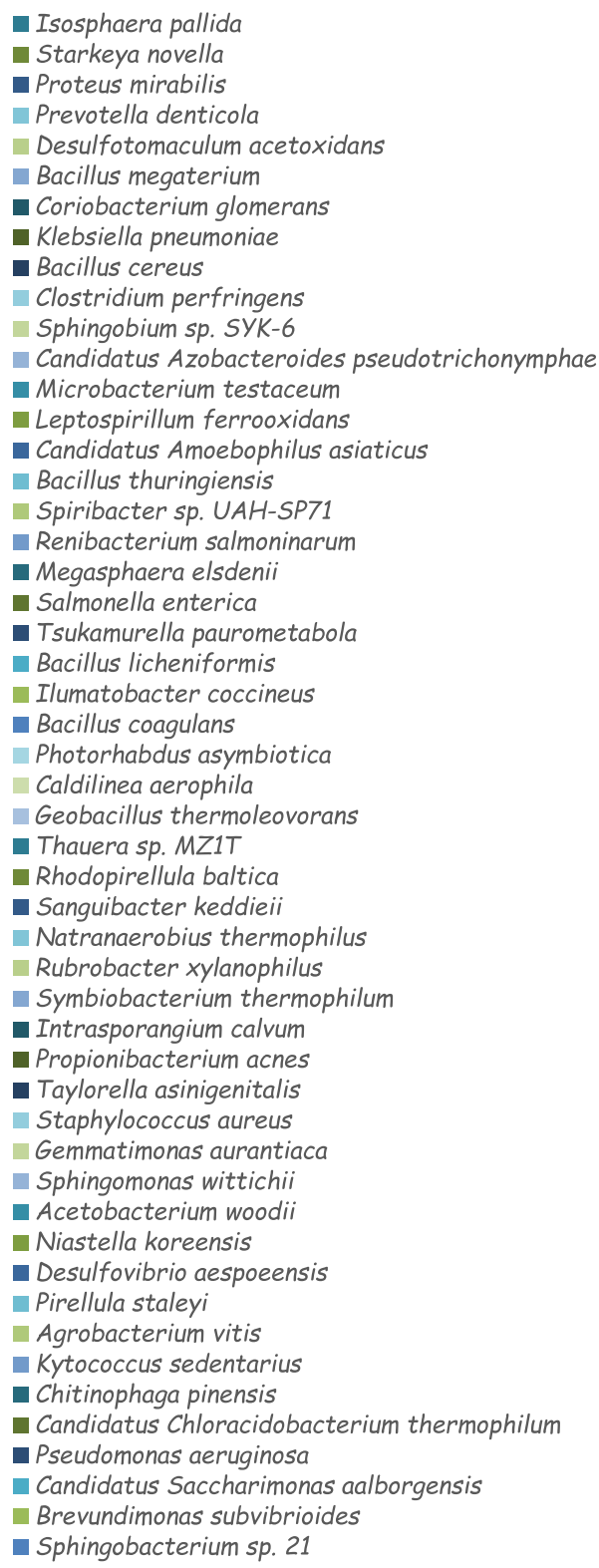

Fig. 6 Species classification of SL1 and SL3 metagenomes. Unclassified reads were not used. Only species with $\geq 10$ sequence reads were used for the analysis 
in the population of Planctomycetes may be attributed to the acidic pH observed in SL3 due to mercury contamination, heavy metal encrustation on the surface of the stalks of some members of Planctomycetes, and the detection of heavy metal resistance genes (Schmidt et al. 1981; Schmidt et al. 1982; Kulichevskaya et al. 2008; Guo et al. 2012).

Though the massive reduction in the concentration of the added inorganic mercury may be connected to the sorption of $\mathrm{Hg}^{2+}$ to iron oxides and organic matter in the soil (Selin 2009), the conversion of $\mathrm{Hg}^{2+}$ to elemental mercury $\left(\mathrm{Hg}^{0}\right)$ via the activities of members of the microbial community possessing the mercury resistant mer gene may have also played a prominent role in the reduction (Gabriel and Williamson 2004). This is because in $\mathrm{Hg}$-resistant microorganisms, the $\mathrm{Hg}^{0}$ evaporates from the microbial cells (Barkay et al. 2003) and the mercury concentration of the soil containing $\mathrm{Hg}$ resistant microorganisms becomes progressively reduced (Wagner-Dobler et al. 2000).

The predominance of the genus Singulisphaera belonging to the phylum Planctomycetes in SL3 metagenome is interesting. Aside from the fact that the $\mathrm{pH}$ of SL3 microcosm $(5.96 \pm 0.25)$ falls within the range of optimum pH (5.1-6.2) of the species S. acidiphila (Kulichevskaya et al. 2008), which perhaps contribute to the dominance of the genus and species in SL3 metagenome, the detection of heavy metal-translocating P-type ATPase in the draft genome of the species S. acidiphila (Guo et al. 2012) may have played a prominent role in the predominance of these species in the mercuryamended SL3 metagenome.

The genera, Brevundimonas and Sphingobacterium are the second and third dominant genera in SL3 metagenome, respectively. The preponderant of these genera in mercury-contaminated environments has been reported by various workers. The genus Brevundimonas, which is significantly enriched in SL3 metagenome has been recovered by several workers from mercury-contaminated environments. Irawati et al. (2012) isolated two highly Hg-resistant (MIC 575 ppm) species, Brevundimonas sp. HgP1 and Brevundimonas sp. HgP2 from a gold mine in Pongkor village, Indonesia. Similarly, Chasanah et al. (2018) reported the isolation of Brevundimonas vesicularis among the mercury-resistant bacterial strains recovered from small-scale gold mine tailings in West Lombok, Indonesia. In addition, using a 10-phylumspecific MerA primer set, Møller et al. (2014) detected the MerA gene from Sphingobacterium spiritivorum isolated from freshwater samples.

Other species with significant presence in SL3 metagenome such as Pedobacter saltans, Sanguibacter keddieii, Proteus mirabilis, Exiguobacterium sp. AT1b, Bacillus megaterium, Desulfobacca acetoxidans, and Acidithiobacillus caldus strain SM-1 have also been recovered from mercury-contaminated matrices, thus, indicating that their presence is not fortuitous. For instance, resistance of Proteus mirabilis isolated from gold-processing mercury-contaminated sites to $40 \mathrm{mg} / \mathrm{l}$ phenyl mercury (Fatimawali et al. 2019) and possession of glutathione S-transferase involved in mercury and other heavy metal resistances by Proteus mirabilis (Zhang et al. 2013) have been reported. Also, Huang et al. (1999 a, b) isolated Bacillus megaterium MB1 from the Minamata bay sediment in Japan that harbors a transposon TnMER11 on its chromosome encoding merR, merT, merP, merA, and $m e r B$ genes for metal-specific activator-repressor, transport, extracellular metal ion binding, mercuric reductase, and organomercurial lyase, respectively. In addition, while Karami et al. (2011) reported the isolation of mercury-resistant Exiguobacterium sp. AT1b, which tolerated $50-75$ ppm mercury (supplied as mercury chloride) from coastal waters in the Persian Gulf, Castro-Severyn et al. (2017) isolated Exiguobacterium sp. SH31 from an altiplanic shallow athalassohaline lake in Chile encoding a wide repertoire of proteins required for cadmium, copper, mercury, tellurium, chromium, and arsenic resistance. Furthermore, Acuna et al. (2013) conducted a genomic analysis of Acidithiobacillus caldus strain SM-1, which revealed a truncated version of the mercuric reductase encoding operon merTPAB, which confers the strain with increased mercury detoxification capacity.

\section{Conclusions}

In summary, this study has revealed that mercury contamination of the agricultural soil impacted negatively on the richness and diversity of the microbial community structure, significantly altered the soil physicochemistry, and massively enriched members of the phylum Planctomycetes and others hitherto not reported to be involved in mercury detoxification.

\section{Supplementary information}

Supplementary information accompanies this paper at https://doi.org/10. 1186/s42269-019-0208-5.

Additional file 1: Figs. S1-S6. Contig-based taxonomic classification of the metagenomes (SL1 and SL3).

\section{Acknowledgements}

Not applicable

Authors' contributions

LBS designed, the work, analyzed the data, and wrote the manuscript. HS, $\mathrm{ZU}$, and FB performed the experiments. All authors read and approved the final manuscript.

Funding

No external funding was received for this study.

Availability of data and materials

All data generated and used in this study are included in this published article and its supplementary information files. 


\section{Ethics approval and consent to participate}

Not applicable

\section{Consent for publication}

All the authors consented to the publication.

\section{Competing interests}

The authors declare that they have no competing interest.

\section{Author details}

'Department of Biological Sciences, Microbiology unit, Summit University, Offa, Nigeria. ${ }^{2}$ Department of Biological Sciences, Microbiology unit, Al-Hikmah University, Ilorin, Nigeria.

\section{Received: 21 June 2019 Accepted: 11 October 2019}

Published online: 27 November 2019

\section{References}

Acuna LG, Cárdenas JP, Covarrubias PC et al (2013) Architecture and gene repertoire of the flexible genome of the extreme acidophile Acidithiobacillus caldus. PLOS ONE 8(11):e78237

Aislabie J, Deslippe JR (2013) Soil microbes and their contribution to soil services. In: Dymond JR (ed) Ecosystem services in New Zealand conditions and trends. Manaaki Whenua Press, Lincoln, pp 143-161

Andrew RWJ, Jackson JM (1996) Pollution and waste management. The natural environment and human impact. Longman Publishers, Singapore, pp 281-297

Azevedo R, Rodriguez E (2012) Phytotoxicity of mercury in plants: a review. J Botany. https://doi.org/10.1155/2012/848614

Babich H, Stotzky G (1985) Heavy metal toxicity to microbe-mediated ecologic processes: a review and potential application to regulatory policies. Environ Res 36:111-137

Bánfalvi G (2011) Heavy metals, trace elements and their cellular effects. In Cellular Effects of Heavy Metals; Bánfalvi G (Ed.), Springer: Dordrecht, the Netherlands, pp.3-28.

Barkay T, Miller SM, Summer AO (2003) Bacterial mercury-resistance from atoms to ecosystems. FEMS Microbiol Rev 27:355-384

Biester H, Müller G, Schöler HF (2002) Binding and mobility of mercury in soils contaminated by emissions from chlor-alkali plants. Sci Total Environ 284 $191-203$

Boening DW (2000) Ecological effects, transport, and fate of mercury: a general review. Chemosphere 40(12):1335-1351

Boszke L, Kowalski A, Glosińska R, Siepak J (2003) Environmental factors affecting speciation of mercury in the bottom sediments: an overview. Polish $J$ Environ Stud 12:5-13

Bruins MR, Kapil S, Oehme FW (2000) Microbial resistance to metals in the environment. Ecotoxicol Environ Saf 45:198-207

Bryan GW, Langston WJ (1992) Bioavailability, accumulation and effects of heavy metals in sediments with special reference to United Kingdom estuaries: a review. Environ Pollut 76(2):89-131

Castro-Severyn J, Ramonsellez F, Valenzuela SL et al (2017) Comparative genomics analysis of a new Exiguobacterium strain from Salar de Huasco reveals a repertoire of stress-related genes and arsenic resistance. Front Microbiol 8:458

Chasanah U, Nuraini Y, Handayanto E (2018) The potential of mercury-resistant bacteria isolated from small-scale gold mine tailings for accumulation of mercury. J Ecol Eng 19(2):236-245

Cheema S, Lavania M, Lal B (2015) Impact of petroleum hydrocarbon contamination on the indigenous microbial community. Ann Microbiol. 66: 359-369

Curtis D, Klaasen JLL (2010) Cassarett \& Doull's essentials of toxicology. McGrawHill, New York, NY, USA

Dreher GB, Follmer LR (2004) Mercury content of Illinois soils. Water Air Soil Pollut 156(1):299-315

Dziewit L, Drewniak L (2016) Heavy metals resistance, metabolism and transformation-genomic, metagenomic and metatranscriptomics studies. In: Dlugonski J (ed) Microbial biodegradation: from omics to function and application. Caister Academic Press, Poole, pp 13-26

Eilers KG, Lauber CL, Knight R, Fierer N (2010) Shifts in bacterial community structure associated with inputs of low molecular weight carbon compounds in soil. Soil Biol Biochem 42:896-903
Fashola MO, Ngole-Jeme VM, Babalola OO (2016) Heavy metal pollution from gold mines: environmental effects and bacterial strategies for resistance. Int J Environ Res Public Health 13:1047

Fatimawali KB, Tallei TE (2019) Potential of organic mercury-resistant bacteria isolated from mercury contaminated sites for organic mercury remediation. Pak J Biol Sci 22:45-50

Fierer N, Bradford MA, Jackson RB (2007) Towards an ecological classification of soil bacteria. Ecology 88:1354-1364

Freitas TA, Li PE, Scholz MB, Chain PS (2015) Accurate read-based metagenome characterization using a hierarchical suite of unique signatures. Nucleic Acids Res 43(10):e69

Gabriel M, Williamson D (2004) Principal biogeochemical factors affecting the speciation and transport of mercury through the terrestrial environment. Environ Geochem Health 26(3-4):421-434

Giller K, Witter E, Mcgrath S (1998) Toxicity of heavy metals to microorganisms and microbial processes in agricultural soils: a review. Soil Biol Biochem 30: 1389-1414

Goldfarb KC, Karaoz U, Hanson CA, Santee CA, Bradford MA, Treseder KK, Wallenstein MD, Brodie EL (2011) Differential growth responses of soil bacterial taxa to carbon substrates of varying chemical recalcitrance. Front Microbiol 2:94

Gundacker C, Gencik M, Hengstschläger M (2010) The relevance of the individual genetic background for the toxicokinetics of two significant neurodevelopmental toxicants: mercury and lead. Mutat Res/Rev Mutat 705:130-140

Guo M, Han X, Jin T et al (2012) Genome sequences of three species in the family Planctomycetaceae. J Bacteriol 194(14):3740-3741

Huang CC, Narita M, Yamagata T, Endo G (1999b) Identification of three merB genes and characterization of a broad-spectrum mercury resistance module encoded by a class II transposon of Bacillus megaterium strain MB1. Gene 239:361-366

Huang CC, Narita M, Yamagata T, Itoh Y, Endo G (1999a) Structure analysis of a class III transposon encoding the mercury resistance of the Gram-positive bacterium Bacillus megaterium MB1, a strain isolated from Minamata Bay, Japan. Gene 234:361-369

Irawati W, Patricia SY, Baskoro AH (2012) A study on mercury-resistant bacteria isolated from a gold mine in Pongkor Village, Bogor, Indonesia. HAYATI J Biosci 19(4):197-200

Israr M, Sahi S, Datta R, Sarkar D (2006) Bioaccumulation and physiological effects of mercury in Sesbania drummondii. Chemosphere 65(4):591-598

Karami K, Zolgharnein H, Assadi MM, Savari A, Dadollahi S (2011) New report on the occurrence of Exiguobacterium sp. AT1b in the Persian Gulf and its resistance to mercury pollution. Curr Res Bacteriol 4(1):23-27

Khan MS, Zaidi A, Wani PA, Oves M (2009) Role of plant growth promoting Rhizobacteria in the remediation of metal contaminated soils. Environ Chem Lett 7:1-19

Kulichevskaya IS, Ivanova AO, Baulina OI, Bodelier PLE, Damste JSS, Dedysh SN (2008) Singulisphaera acidiphila gen. nov., sp. nov., a non-filamentous, Isosphaera-like planctomycete from acidic northern wetlands. Int J Syst Evol Microbiol 58:1186-1193

Langmead B, Salzberg SL (2012) Fast gapped-read alignment with Bowtie-2. Nat Methods 9(4):357-359

Lapanje A, Zrimec A, Drobne D, Rupnik M (2010) Long-term Hg pollutioninduced structural shifts of bacterial community in the terrestrial isopod (Porcellio scaber) gut. Environ Pollut 154:3186-3193

Li H, Durbin R (2009) Fast and accurate short read alignment with BurrowsWheeler transform. Bioinformatics 25(14):1754-1760

Li P-E, Lo C-C, Anderson JJ et al (2017) Enabling the democratization of the genomics revolution with a fully integrated web-based bioinformatics platform. Nucleic Acids Res 45(1):67-80

Lo C-C, Chain PSG (2014) Rapid evaluation and quality control of next generation sequencing data with FaQCs. BMC Bioinform 15:366

Møller AK, Barkay T, Hansen MA, Norman A, Hansen LH, Sørensen SJ, Boyd ES, Kroer N (2014) Mercuric reductase genes (merA) and mercury resistance plasmids in high arctic snow, freshwater and sea-ice brine. FEMS Microbiol Ecol 87:52-63

Montecchia MS, Tosi M, Soria MA, Vogrig JA, Sydorenko O, Correa OS (2015) Pyrosequencing reveals changes in soil bacterial communities after conversion of Yungas forests to agriculture. PLoS One 10:e0119426

Nies D (1999) Microbial heavy-metal resistance. Appl Microbiol Biotechnol 51:730-750

Nies DH, Silver S (1995) lon efflux systems involved in bacterial metal resistances. J Ind Microbiol 14:186-199 
Ortega-Villasante C, Rellán-Alvarez R, Del Campo FF, Carpena-Ruiz RO, Hernandez LE (2005) Cellular damage induced by cadmium and mercury in Medicago sativa. J Exp Botany 56(418):2239-2251

Peng Y, Leung HC, Yiu SM, Chin FY (2012) IDBA-UD: a de novo assembler for single-cell and metagenomic sequencing data with highly uneven depth. Bioinformatics 28(11):1420-1428

Rasmussen LD, Sorensen SJ (2001) Effects of mercury contamination on the culturable heterotrophic, functional and genetic diversity of the bacterial community in soil. FEMS Microbiol Ecol 36:1-9

Rasmussen LD, Zawasdsky C, Binnerup SJ, Oregaard G, Sorensen SJ, Kroer N (2008) Cultivation of hard-to-culture subsurface mercury-resistant bacteria and discovery of new merA gene sequence. Appl Environ Microbiol 74(12): 3795-3803

Robinson JB, Tuovinen OH (1984) Mechanisms of microbial resistance and detoxification of mercury and organomercury compounds: physiological, biochemical, and genetic analyses. Microbiol Rev 48(2):95-124

Romaniuk K, Ciok A, Decewicz P et al (2018) Insight into heavy metal resistome of soil psychrotolerant bacteria originating from King George Island (Antarctica). Polar Biol 41:1319-1333

Salam LB (2018) Detection of carbohydrate-active enzymes and genes in a spent engine oil-perturbed agricultural soil. Bull Natl Res Cent 42:10

Salam LB, Ilori MO, Amund OO, Numata M, Horisaki T, Nojiri H (2014) Carbazole angular dioxygenation and mineralization by bacteria isolated from hydrocarbon-contaminated tropical African soil. Environ Sci Pollut Res 21: 9311-9324

Salam LB, Ishaq A (2019) Biostimulation potentials of corn steep liquor in enhanced hydrocarbon degradation in chronically polluted soil. 3 Biotech 9:46.

Salam LB, Obayori OS, Nwakorie FO, Suleiman A, Mustapha R (2017) Metagenomic insight into effects of spent oil perturbation on the microbial community composition and function in a tropical agricultural soil. Environ Sci Pollut Res 24:7139-7159. https://doi.org/10.1007/s11356-017-8364-3

Schmidt JM, Sharp WP, Starr MP (1981) Manganese and iron encrustations and other features of Planctomyces crassus Hortobagyi 1965, morphotype lb of the Blastocaulis-Planctomyces group of budding and appendaged bacteria, examined by electron microscopy and X-ray micro-analysis. Curr Microbiol 5: 241-246

Schmidt JM, Sharp WP, Starr MP (1982) Metallic oxide encrustations of the non prosthecate stalks of naturally occurring populations of Planctomyces bekefii. Curr Microbiol 7:389-394

Segata N, Waldron L, Ballarini A, Narasimhan V, Jousson O, Huttenhower C (2012) Metagenomic microbial community profiling using unique clade-specific marker genes. Nat Methods 9:811-814

Selin NE (2009) Global biogeochemical cycling of mercury: a review. Annu Rev Environ Resour 34:43-63

Silver S, le Phung T (2005) A bacterial view of the periodic table: genes and proteins for toxic inorganic ions. J Ind Microbiol Biotechnol 32:587-605

Spain AM, Krumholz LR, Elshahed MS (2009) Abundance, composition, diversity and novelty of soil Proteobacteria. ISME Journal 9:992-1000

Sparks DL (2005) Toxic metals in the environment: the role of surfaces. Elements 1(4):193-197

Toth G, Hermann T, DaSilva MR, Montanarella L (2016) Heavy metals in agricultural soils of the European Union with implications for food safety. Environ Int 88:299-309

Trivedi P, Delgado-Baquerizo M, Anderson IC, Singh BK (2016) Response of soil properties and microbial communities to agriculture: implications for primary productivity and health indicators. Front Plant Sci 7:990. https://doi.org/10. 3389/fpls.2016.00990

UNEP (2013) Environmental risks and challenges of anthropogenic metals flows and cycles. In: vanderVoet E, Salminen R, Eckelman M, Mudd G, Norgate T, Hischier R (Eds.), A Report of the Working Group on the Global Metal Flows to the International Resource Panel, p.231.

Valko M, Rhodes C, Moncol J, Izakovic M, Mazur M (2006) Free radicals, metals and antioxidants in oxidative stress-induced cancer. Chem Biol Interact 160:1-40

Wagner-Dobler L, von Canstein H, Li Y, Timmis KN, Deckwer W-D (2000) Removal of mercury from chemical wastewater by microorganisms in technical scale. Environ Sci Technol 34:4628-4634

Wang DY, Qing CL, Guo TY, Guo YJ (1997) Effects of humic acid on transport and transformation of mercury in soil-plant systems. Water Air Soil Pollut 95(1-4):35-43

Weiss B, Clarkson TW, Simon W (2002) Silent latency periods in methylmercury poisoning and in neurodegenerative disease. Environ Health Perspect 110: 851-854
WHO/FAO (2001). Codex alimentarius commission. Food additives and contaminants. Joint FAONHO Food Standards Programme, ALINORM 10/12A.

Wood DE, Salzberg SL (2014) Kraken: ultrafast metagenomic sequence classification using exact alignments. Genome Biol 15(3):R46

Wyszkowska J, Borowik A, Kucharski MA, Kucharski J (2013) Effect of cadmium, copper and zinc on plants, soil microorganisms and soil enzymes. J Elementol 18:2587-2602

Yin C, Mueth N, Hulbert S (2017) Bacterial community on wheat grown under long-term conventional tillage and no-till in the Pacific Northwest of the United States. Phytobiomes J 1(2):83-90

Yuan L, Zhi W, Liu Y, Karyala S, Vikesland PJ, Chen X, Zhang H (2015) Lead toxicity to the performance, viability, and community composition of activated sludge microorganisms. Environ Sci Technol 49:824-830

Zhang W, Yin K, Li B, Chen L (2013) A glutathione S-transferase from Proteus mirabilis involved in heavy metal resistance and its potential application in removal of $\mathrm{Hg}^{2+}$. J Hazardous Mater 261:646-652

\section{Publisher's Note}

Springer Nature remains neutral with regard to jurisdictional claims in published maps and institutional affiliations.

\section{Submit your manuscript to a SpringerOpen ${ }^{\circ}$ journal and benefit from:}

- Convenient online submission

- Rigorous peer review

- Open access: articles freely available online

- High visibility within the field

- Retaining the copyright to your article

Submit your next manuscript at $\boldsymbol{\nabla}$ springeropen.com 